\title{
LÚPUS ERITEMATOSO SISTÊMICO ASSOCIADO A DISFUNÇÃO TEMPOROMANDIBULAR: RELATO DE CASO
}

Max Roberto MANFROI, Paulo Afonso CUNALI, Daniel BONOTTO

O Lúpus Eritematoso Sistêmico (LES) é uma doença inflamatória crônica multissistêmica, de base autoimune, caracterizada pela produção de múltiplos auto-anticorpos, formação de imunocomplexos e comprometimento inflamatório de diversos orgãos e tecidos, acometendo mais as mulheres, numa proporção de 9:1. O LES pode apresentar-se associado a distúrbios articulares secundários, podendo, inclusive, afetar as articulações temporomandibulares. Embora seja uma associação rara, este estudo tem por objetivo relatar o caso de uma paciente de 56 anos, com diagnóstico de LES, que procurou 0 especialista em DTM e DOF com queixa de dor temporomandibular articular e muscular e limitação da função mandibular, mesmo estando medicada por médico reumatologista. Após tratamento para DTM com placa oclusal, exercícios mandibulares e visco-suplementação das ATM, a paciente apresentou melhora para dor e função mandibular. Conclui-se que a participação do especialista em DTM e DOF numa equipe multidisciplinar mostra-se importante para o controle da sintomatologia e melhora da qualidade de vida de pacientes com LES, com manifestação secundária nas ATM.

Palavras-Chave: Articulação Temporomandibular; ATM; Lúpus Eritematoso Sistêmico. 